\title{
Spironolactone versus observation in the treatment of acute central serous chorioretinopathy
}

\author{
Xinghong Sun, ${ }_{1}$ Yuanlu Shuai, ${ }^{2}$ Wangyi Fang, ${ }^{3}$ Jia Li, ${ }^{3}$ Weizhong $\mathrm{Ge}^{2}$ Songtao Yuan, ${ }^{3}$ \\ Qinghuai Liu ${ }^{3}$
}

'Department of Ophthalmology, Third People's Hospital of Changzhou, Changzhou, China 'Department of Ophthalmology, Yixing People's Hospital, Yixing, China

${ }^{3}$ Department of Ophthalmology, The First Affiliated Hospital of Nanjing Medical University, Nanjing, China

\section{Correspondence to}

Dr Songtao Yuan, Department of Ophthalmology, The First Affiliated Hospital of Nanjing Medical University, Nanjing 210029, China; yuansongtao@ vip.sina.com and Weizhong $\mathrm{Ge}$, Department of Ophthalmology, Yixing People's Hospital, Yixing 214200,China; staff326@ yxph.com

SY and WG are cocorresponding authors. SY is responsible for proofs and payment. XS and YS are co-first authors and they contributed equally to this work.

Received 24 July 2017 Revised 13 September 2017 Accepted 30 September 2017 Published Online First 31 October 2017

Check for updates

To cite: Sun $X$, Shuai $Y$, Fang W, et al. Br J Ophthalmol 2018:102:1060-1065.

\section{ABSTRACT}

Purpose To evaluate the efficacy of oral spironolactone in patients with acute central serous chorioretinopathy (CSC).

Methods This is a prospective, randomised controlled clinical study. Thirty patients with acute CSC were the participants, including 18 patients who were treated with spironolactone (40 mg orally, twice daily) for 2 months in the experimental group and 12 patients who received observation in the control group. Main outcome measures included the proportion of eyes achieving complete resolution of subretinal fluid (SRF), changes in central macular thickness (CMT), the height of SRF (SRFH), best corrected visual acuity (BCVA) and subfoveal choroidal thickness (SFCT). The follow-up period was 2 months.

Results Complete resolution of SRF was achieved in $55.6 \%(10 / 18)$ and $8.3 \%(1 / 12)$ of the eyes in the treatment group and the control group, respectively, at 2 months $(p=0.018)$. The mean CMT and SRFH decreased significantly at each visit in both groups $(p<0.05)$, and there was significant difference between the two groups at 2 months ( $p<0.05$ and $p<0.05$, respectively). BCVA (in logarithm of the minimum angle of resolution; mean) improved in both groups at 2 months $(p<0.05)$. In the treatment group, the mean baseline SFCT significantly decreased from $502.50 \pm 87.38 \mu \mathrm{m}$ to $427.44 \pm 74.37 \mu \mathrm{m}$ at 2 months $(p<0.01)$, while the change from baseline (from $480.33 \pm 102.38 \mu \mathrm{m}$ to $463.75 \pm 100.63 \mu \mathrm{m}$ ) was not significant in the control group $(p=0.195)$. But the differences between the two groups in BCVA and SFCT were not significant.

Conclusions Oral spironolactone is more effective with a faster absorption of SRF than observations. It is a promising treatment for acute CSC.

Trial registration number ChiCTR-IPR-16008428, Results.

\section{INTRODUCTION}

Central serous chorioretinopathy (CSC) is a disorder characterised by serous retinal detachment (SRD) and/or retinal pigment epithelial (RPE) detachment at the posterior pole. The overall incidence of the disease is 5.8 per 100000 people in a population-based study, with approximately six times higher incidence in men than in women. ${ }^{1}$ CSC is generally benign and self-limiting. The majority of patients with acute CSC achieved resolution spontaneously in 3 months, ${ }^{2}$ and $25 \%$ of patients have subretinal fluid (SRF) resolution at 2 months during the natural course of $\mathrm{CSC}^{3}$ so observation is often the first-line therapy in acute
CSC for ophthalmologists. Recurrence cannot be avoided whether treated or not. ${ }^{4}$ Cases that do not resolve spontaneously may turn into chronic CSC.

The exact pathogenesis of CSC is not clear so far. Choroidal vascular abnormality, including choroidal vascular hyperpermeability and choroidal vascular dilation, was demonstrated by indocyanine green angiography. ${ }^{67}$ Increased choroidal thickness was detected by the application of enhanced depth imaging optical coherence tomography (EDI-OCT) in patients with CSC. ${ }^{89}$ These findings further illustrated the hypothesis that choriocapillaris hyperpermeability resulted in the occurrence of CSC. ${ }^{10}$

Endogenous and exogenous corticosteroids are associated with the development of CSC. However, the exact mechanism of corticosteroids is not clear in the pathogenesis of CSC. ${ }^{11}$ Recently, Zhao et al demonstrated that mineralocorticoid receptor (MR) is expressed in ganglion cells, cells of the inner nuclear layer and retinal Müller glial cells (RMGs) in rat eyes. Aldosterone controls retinal fluid homeostasis through upregulating the ion and water channel, which is expressed in the apical region of RMGs. ${ }^{12}$ Subsequently, they proved that aldosterone could increase the expression of the channel $\mathrm{KCa} 2.3$, which was related to vasodilation and expressed only in the endothelium of choroidal vessels. Zhao et $a l^{13}$ proposed a novel pathogenesis that excessive activation of MR signalling pathway induced dilation and leakage of choroid vessels, resulting in thickening of choroid, leading to the occurrence of CSC. Based on this assumption, a series of studies that reported the use of MR antagonist (MRa) in patients with chronic or recurrent CSC showed encouraging results, including anatomical and functional improvement, proposing that MRa may be a novel treatment for patients with CSC with persistent SRF. ${ }^{14-24}$ So we proposed that oral spironolactone may also be more effective in treating patients with acute CSC with a faster absorption of SRF than the natural course. The aim of this study is to evaluate if oral spironolactone will contribute to shortening the episode duration in patients with acute CSC.

\section{Study design}

This was a prospective, randomised and controlled clinical study. From January 2015 to January 2016, we recruited 30 eyes of 30 patients who were diagnosed with acute CSC at the Department of Ophthalmology of The First Affiliated Hospital of Nanjing Medical University, China. The study stuck 
to the tenets of the Declaration of Helsinki. The study's clinical trial registration number is ChiCTR-IPR-16008428.

\section{Study subjects}

Inclusion criteria were as follows: (1) patients aged more than 18 years, (2) visual symptom $\leq 3$ months and (3) the first CSC attack. Exclusion criteria were (1) chronic CSC (duration $>3$ months) or recurrent chronic CSC, (2) macular diseases such as polypoidal choroidal vasculopathy and age-related macular degeneration, (3) eyes with a history of previous treatment, including laser photocoagulation (LP), photodynamic therapy (PDT) or intravitreal antivascular endothelial growth factor (anti-VEGF) injections, (4) pregnancy, history of steroid use and systemic diseases such as endogenous hypercortisolism, and diabetics, and (5) patients with contraindications against spironolactone (severe liver or kidney disease, serum potassium level $>5.5 \mathrm{mmol} / \mathrm{L}$ ).

Thirty eyes were randomly assigned into two groups: the experimental group, in which patients were treated with oral MRa (spironolactone $40 \mathrm{mg}$ orally, twice daily) for 2 months, and the control group, in which patients were observed without any treatment. Eighteen eyes were enrolled in the MRa group and 12 eyes were enrolled in the observation group.

\section{Baseline and follow-up}

At baseline, a complete ophthalmic examination, including best corrected visual acuity (BCVA), slit lamp biomicroscopy, fundus fluorescein angiography (FFA) (Heidelberg HRA; Heidelberg Engineering, Heidelberg, Germany) and EDI-OCT (Cirrus HD-OCT; Carl Zeiss Meditec, Dublin, California, USA), was performed. Blood pressure (BP), serum potassium level and serum aldosterone level were also tested before inclusion. At 1 and 2 months, BCVA and EDI-OCT were performed again. In the MRa group, if the patients showed hyperkalaemia, hypotension or other intolerable complications of the drug, the treatment was stopped. The central macular thickness (CMT) was provided automatically using the macular thickness map measured by OCT. The height of SRF (SRFH) was measured manually between the outer segment line and the RPE layer at the foveal centre. The subfoveal choroidal thickness (SFCT) was measured manually between the RPE layer and the inner surface of the sclera. The mean values of measurements of SRFH and SFCT from the two independent experienced observers (YS and WF) were obtained for further analysis.

\section{Statistics}

Snellen BCVA was converted to a logarithm of the minimum angle of resolution (logMAR) for statistical analysis. Data are presented as mean \pm SD. All data were analysed by SPSS V.20.0. Variables before and after treatment were compared using the Wilcoxon signed-rank test in each group. Fisher's exact test was used to compare differences in gender, the number of patients with leakage point in FFA and the rate of complete resolution of SRF between the two groups. The Mann-Whitney U test was used to compare BCVA, CMT, SRFH and SFCT between the two groups. A p value $<0.05$ was considered statistically significant.

\section{RESULTS}

\section{Patient demographics and clinical characteristics}

In this study, a total of 30 eyes (18 eyes, MRa group; 12 eyes, observation group) in 30 patients with acute CSC were enrolled and randomised into two groups. The mean ages in the treatment group and the control group were $43.33 \pm 8.22$ years
Table 1 Baseline demographic characteristics in the two study groups

\begin{tabular}{|c|c|c|c|}
\hline & MRa group $(n=18)$ & $\begin{array}{l}\text { Control group } \\
(n=12)\end{array}$ & $\mathrm{p}$ Value \\
\hline Age (years) & $43.33 \pm 8.22$ & $44.08 \pm 9.08$ & $1.000^{*}$ \\
\hline Gender (male:female) & $15: 3$ & $10: 2$ & $1.000 t$ \\
\hline $\begin{array}{l}\text { Duration of symptoms } \\
\text { (weeks) }\end{array}$ & $3.42 \pm 2.69$ & $3.21 \pm 1.53$ & $0.662^{*}$ \\
\hline BCVA (logMAR) & $0.28 \pm 0.22$ & $0.28 \pm 0.21$ & $0.787^{*}$ \\
\hline CMT $(\mu \mathrm{m})$ & $535.67 \pm 116.94$ & $501.33 \pm 149.39$ & $0.439 *$ \\
\hline Aldosterone level (ng/dL) & $226.04 \pm 147.97$ & $158.50 \pm 103.44$ & $0.087^{*}$ \\
\hline SRFH $(\mu \mathrm{m})$ & $340.61 \pm 126.84$ & $315.17 \pm 154.17$ & $0.602^{*}$ \\
\hline $\mathrm{SFCT}(\mu \mathrm{m})$ & $502.50 \pm 87.38$ & $480.33 \pm 102.38$ & $0.602^{*}$ \\
\hline Patients with leakage point & $16 / 18$ & $11 / 12$ & $1.000 t$ \\
\hline
\end{tabular}

Values are mean \pm SD unless otherwise noted.

*Mann-Whitney $U$ test.

†Fisher's exact test.

BCVA, best corrected visual acuity; CMT, central macular thickness; logMAR, logarithm of the minimum angle of resolution; $\mathrm{MRa}$, mineralocorticoid receptor antagonist; SFCT, subfoveal choroidal thickness; SRFH, height of subretinal fluid.

and 44.42 \pm 8.91 years $($ mean $\pm S D)$, respectively $(\mathrm{p}=1.000)$. The male-to-female ratio between the two groups also did not demonstrate a significant difference $(p=1.000)$. Duration of symptoms was $3.42 \pm 2.69$ weeks in the MRa group and $3.21 \pm 1.53$ weeks in the observation group $(\mathrm{p}=0.662)$. The aldosterone level was $226.04 \pm 147.97 \mathrm{ng} / \mathrm{dL}$ in the MRa group and $158.50 \pm 103.44 \mathrm{ng} / \mathrm{dL}$ in the control group $(\mathrm{p}=0.087)$. The number of patients with leakage point in FFA was 16 in the MRa group and 11 in the control group $(p=1.000)$. Baseline BCVA (logMAR), CMT, SRFH and SFCT were not significantly different between the two groups $(p=0.787, p=0.439, p=0.602$ and $p=0.602$, respectively). The baseline demographic characteristics of both groups are summarised in table 1 .

\section{Best corrected visual acuity}

The mean BCVA (in logMAR) at baseline, 1 month and 2 months in both groups is shown in table 2 and figure 1 . In the treatment group, the mean BCVA was $0.25 \pm 0.18$ at baseline, $0.14 \pm 0.15$ at 1 month and $0.05 \pm 0.09$ at 2 months. The BCVA significantly improved gradually compared with baseline in 1 and 2 months $(\mathrm{p}<0.05$ and $\mathrm{p}<0.01$, respectively). The mean BCVA of the control group was $0.25 \pm 0.22$ at baseline, $0.19 \pm 0.20$ $(\mathrm{p}=0.197)$ at 1 month and $0.14 \pm 0.18(\mathrm{p}<0.05)$ at 2 months. The BCVA significantly improved only in 2 months in the observation group. However, there was no significant difference in BCVA between the two groups at baseline $(p=0.787), 1$ month $(\mathrm{p}=0.645)$ and 2 months $(\mathrm{p}=0.124)$.

\section{Central macular thickness}

The mean changes of CMT at baseline, 1 and 2 months in both groups are summarised in table 2 and figure 1 . In the MRa group, the mean CMT decreased significantly from $535.67 \pm 116.94 \mu \mathrm{m}$ at baseline to $354.88 \pm 108.64 \mu \mathrm{m}$ at 1 month $(\mathrm{p}=0.001)$, and to $248.72 \pm 45.58 \mu \mathrm{m}$ at 2 months $(\mathrm{p}<0.001)$. The mean CMT in the observation group was $501.33 \pm 149.39 \mu \mathrm{m}$ at baseline, which also decreased significantly to $401.36 \pm 125.33 \mu \mathrm{m}$ at 1 month $(\mathrm{p}<0.05)$ and to $307.33 \pm 95.42 \mu \mathrm{m}$ at 2 months $(\mathrm{p}<0.05)$. No significant difference was observed in mean CMT between the two groups at baseline and 1 month $(p=0.439$ and $p=0.422$, respectively). There was a significant difference in the mean CMT between the two groups at 2 months $(p<0.05)$. 
Table 2 Changes in BCVA, CMT, SRFH and SFCT during the followup period in the treatment and control groups

\begin{tabular}{|c|c|c|c|c|}
\hline & & Baseline & 1 Month & 2 Months \\
\hline \multirow[t]{2}{*}{$\begin{array}{l}\text { LogMAR } \\
\text { BCVA }\end{array}$} & $\begin{array}{l}\text { Treatment } \\
\text { group }\end{array}$ & $0.25 \pm 0.18$ & $0.14 \pm 0.15^{*}$ & $0.05 \pm 0.09 *$ \\
\hline & $\begin{array}{l}\text { Control } \\
\text { group }\end{array}$ & $0.25 \pm 0.22$ & $0.19 \pm 0.20$ & $0.14 \pm 0.18^{*}$ \\
\hline$p$ & & 0.787 & 0.645 & 0.124 \\
\hline \multirow[t]{2}{*}{ CMT $(\mu \mathrm{m})$} & $\begin{array}{l}\text { Treatment } \\
\text { group }\end{array}$ & $535.67 \pm 116.94$ & $354.88 \pm 108.64 *$ & $248.72 \pm 45.58 \dagger$ \\
\hline & $\begin{array}{l}\text { Control } \\
\text { group }\end{array}$ & $501.33 \pm 149.39$ & $401.36 \pm 125.33^{*}$ & $307.33 \pm 95.42$ * \\
\hline$p$ & & 0.439 & 0.422 & $0.048^{*}$ \\
\hline \multirow[t]{2}{*}{ SRFH $(\mu \mathrm{m})$} & $\begin{array}{l}\text { Treatment } \\
\text { group }\end{array}$ & $340.61 \pm 126.84$ & $155.75 \pm 116.31$ * & $43.22 \pm 61.02 \dagger$ \\
\hline & $\begin{array}{l}\text { Control } \\
\text { group }\end{array}$ & $315.17 \pm 154.17$ & $199.27 \pm 131.79 *$ & $114.58 \pm 97.40$ * \\
\hline $\mathrm{p}$ & & 0.602 & 0.512 & $0.017^{*}$ \\
\hline \multirow[t]{2}{*}{$\mathrm{SFCT}(\mu \mathrm{m})$} & $\begin{array}{l}\text { Treatment } \\
\text { group }\end{array}$ & $502.50 \pm 87.38$ & $456.00 \pm 81.11 \dagger$ & $427.44 \pm 74.37 \dagger$ \\
\hline & $\begin{array}{l}\text { Control } \\
\text { group }\end{array}$ & $480.33 \pm 102.38$ & $456.18 \pm 98.94$ & $463.75 \pm 100.63$ \\
\hline $\mathrm{p}$ & & 0.602 & 0.942 & 0.215 \\
\hline
\end{tabular}

Data are presented as mean \pm SD.

*Indicates significant difference from baseline ( $p<0.05$, Wilcoxon signed-rank test). tIndicates significant difference from baseline ( $p<0.01$, Wilcoxon signed-rank test). BCVA, best corrected visual acuity; CMT, central macular thickness; logMAR, logarithm of the minimum angle of resolution; SFCT subfoveal choroidal thickness; SRFH, height of subretinal fluid.

\section{Subretinal fluid}

Two eyes in the treatment group showed no existence of SRF and none of the observation group showed complete regression of $\mathrm{SRF}$ at 1 month. Complete resolution of SRF in the MRa group and the control group was achieved in 55.6\% (10/18) and 8.3\%

A

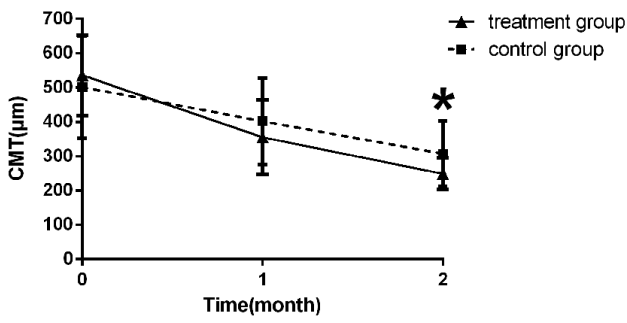

C

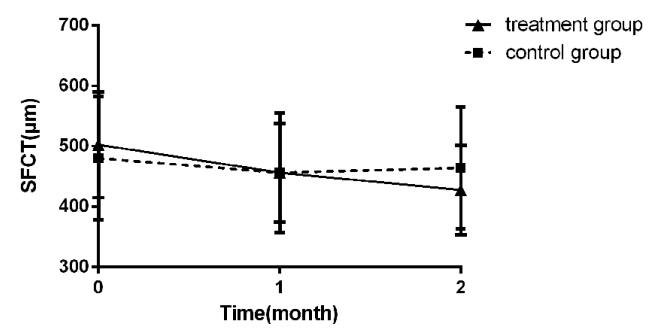

$(1 / 12)$ of the eyes, respectively, at 2 months $(p=0.018)$. In the MRa group, SRFH decreased significantly from $340.61 \pm 126.84 \mu \mathrm{m}$ at baseline to $155.75 \pm 116.31 \mu \mathrm{m}$ at 1 month $(\mathrm{p}=0.001)$, and to $43.22 \pm 61.02 \mu \mathrm{m}$ at 2 months $(\mathrm{p}<0.001)$. In the observation group, a significant decrease from $315.17 \pm 154.17 \mu \mathrm{m}$ at baseline to $199.27 \pm 131.79 \mu \mathrm{m}$ at 1 month $(\mathrm{p}<0.05)$, and to $114.58 \pm 97.40 \mu \mathrm{m}$ at 2 months $(\mathrm{p}<0.05)$, was also shown. No significant difference was observed between the two groups at 1 month $(p=0.512)$. A significant difference in SRFH between groups was observed at 2 months $(\mathrm{p}<0.05)$. The mean changes of SRFH at baseline, 1 and 2 months in both groups are summarised in table 2 and figure 1. Changes of macular maps and OCT of four patients with CSC at baseline and at 2 months are shown in figure 2 .

\section{Subfoveal choroidal thickness}

Mean SFCT measurements at baseline and during the follow-up period are summarised for both groups in table 2 and figure 1 . The mean SFCT in the control group was $480.33 \pm 102.38 \mu \mathrm{m}$ at baseline, and decreased slightly to $463.75 \pm 100.63 \mu \mathrm{m}$ at 2 months. However, the change from baseline was not significant $(p=0.195)$. In the treatment group, the mean baseline SFCT significantly decreased from $502.50 \pm 87.38 \mu \mathrm{m}$ to $456.00 \pm 81.11 \mu \mathrm{m}$ at 1 month $(\mathrm{p}=0.000)$ and $427.44 \pm 74.37 \mu \mathrm{m}$ at 2 months $(\mathrm{p}=0.000)$. However, no significant difference was observed between the two groups at baseline and at 1 and 2 months $(p=0.602, p=0.942$ and $\mathrm{p}=0.215$, respectively).

\section{Safety}

At each visit, none of the patients in the treatment group developed serious ocular or systemic side effects related to spironolactone, such as hyperkalaemia or hypotension.

\section{B}

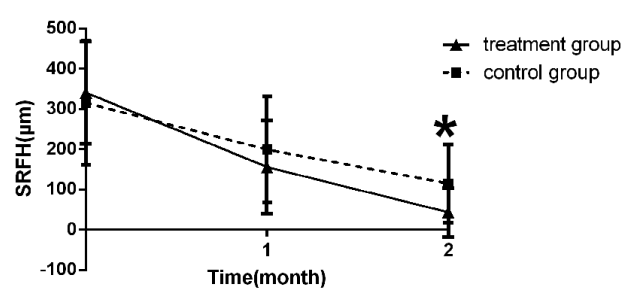

D

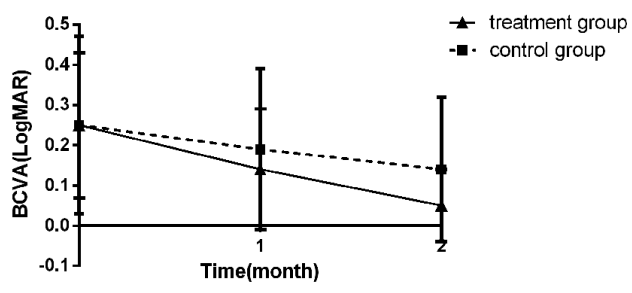

Figure 1 (A) On OCT evaluation, CMT decreased significantly after 2 months of treatment in both groups. (B) On OCT evaluation, SRFH decreased significantly after 2 months of treatment in both groups. (C) The mean baseline SFCT was significant at 2 months in the treatment group, while the change from baseline was not significant in the control group. (D) The BCVA (logMAR) was significantly improved compared with baseline at 2 months. *Indicates a significant difference between the treatment and control groups ( $p<0.05$, Mann-Whitney U test). Error bars represent $S E s$ of the mean. BCVA, best corrected visual acuity; CMT, central macular thickness; logMAR, logarithm of the minimum angle of resolution; OCT, optical coherence tomography; SFCT, subfoveal choroidal thickness; SRFH, height of subretinal fluid. 

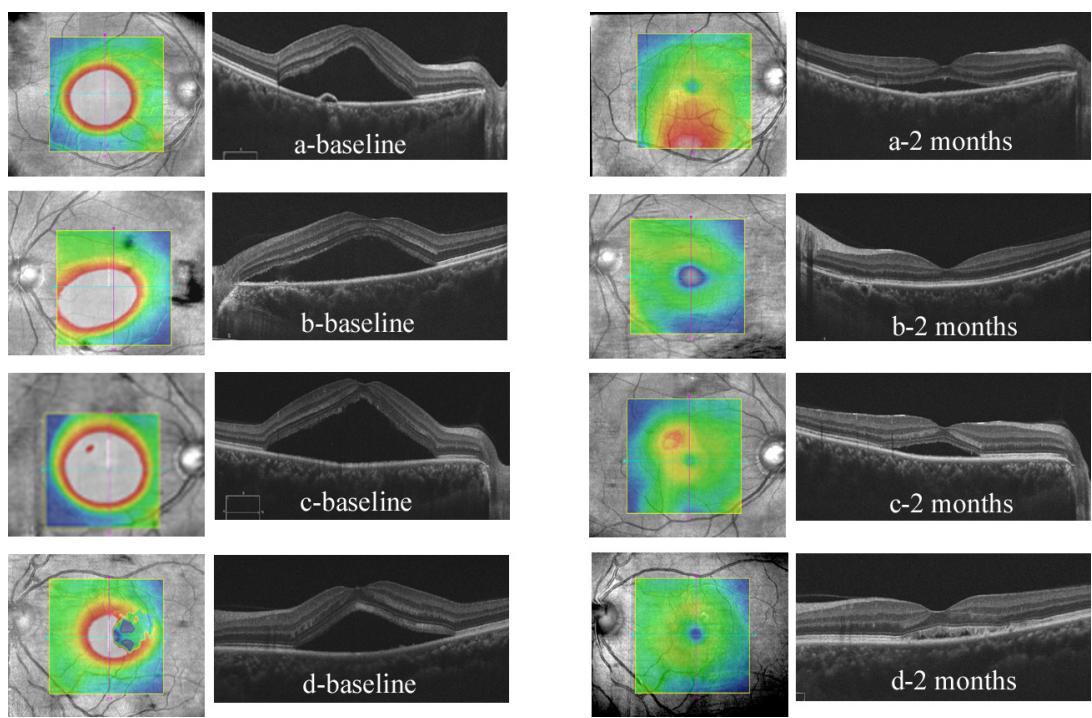

Figure 2 Changes of macular maps and optical coherence tomography of four patients with central serous chorioretinopathy at baseline and at 2 months (patients $a$ and $b$ received oral spironolactone for 2 months, while patients $\mathrm{c}$ and $\mathrm{d}$ received observation).

\section{DISCUSSION}

The course of CSC is very variable. According to its clinical course, CSC can be classified into acute CSC or chronic CSC. The acute form is characterised by the presence of SRD, clinically detectable on fundus examination and on OCT, with limited focal or multifocal RPE alterations that may be limited to small pigment epithelial detachments, and leakage through the RPE on FFA. The SRD usually resolves within 3-4 months, leaving in most cases no long-term symptoms, except colour discrimination defects in some patients. ${ }^{25}$ Chronic CSC represents approximately 5\% of CSC cases ${ }^{26}$ and is characterised by areas of widespread diffuse RPE pigmentary abnormalities, including RPE atrophy which can be severe enough to cause geographic atrophy, pigment clumping in the posterior pole and chronic shallow SRD. ${ }^{27}$

Although CSC is generally self-limiting, some patients may have a strong desire for recovery from disease. To shorten the duration, treatments for acute CSC including conventional LP, PDT and anti-VEGF injections are performed by ophthalmologists. However, there are some drawbacks. LP shortens the course of CSC about 2 months but has no effect on the final visual improvement, ${ }^{28} 29$ and it may induce scotoma, declined contrast sensitivity, RPE atrophy and choroidal neovascularisation. ${ }^{28} 3031$ Although PDT with half-dose verteporfin in treating acute CSC shows better BCVA, faster SRF resolution and higher retinal function than placebo, ${ }^{32} 33$ complications such as RPE atrophy, choriocapillary ischaemia and secondary choroidal neovascularisation have also been reported. ${ }^{34} 35 \mathrm{~A}$ meta-analysis shows that anti-VEGF injection shortens the duration and shows better BCVA early, but the benefits no longer existed at 3 and 6 months after injection. ${ }^{36}$ Besides, the role of VEGF playing in the pathogenesis of CSC remains uncertain.

The underlying mechanism of action of MRa for treatment of CSC is postulated to be the overaction of MR pathways. Previous studies ${ }^{14-22}$ have used the MRa to treat patients with chronic or recurrent or refractory CSC, confirming a positive influence in most cases, a decrease of SRF and CMT, and also improvement or stabilisation of BCVA. The complete resolution differed from each other due to different treatment methods, which achieved 25\%-67\%. These patients were administrated with eplerenone or spironolactone or both drugs sequentially with a dosage of $25-100 \mathrm{mg} /$ day. In our study we treated 18 patients with acute CSC with a dosage up to $80 \mathrm{mg} /$ day, similar to other studies. A decrease in SFCT has been previously observed after the therapy, further illustrating the role of choroidal vasculature in central serous chorioretinopathy pathogenesis. 19202223

Although spironolactone has a 20-fold higher binding affinity for the MR in vitro than eplerenone, it is associated with progestogenic and antiandrogenic adverse effects because of the similar structure to the progesterone. ${ }^{37}$ Kapoor and Wagner $^{21}$ reported that there was a statistically significant increase in the incidence of side effects with spironolactone than eplerenone. Struthers et al reported that eplerenone costs between six and seven times more than spironolactone. ${ }^{38}$ Daruich et al and Kapoor and Wagner observed no difference when evaluating the efficacy of eplerenone and spironolactone in treating chronic CSC, ${ }^{19} 21$ and Pichi et al ${ }^{39}$ reported that spironolactone was statistically superior to eplerenone in improving BCVA of patients with chronic CSC. Taking the cost, the affinity and the efficacy into account, we used spironolactone rather than eplerenone as the MRa to treat acute CSC in this study. Considering that the patients have a duration of at least $0.5-1$ month when they come to see the doctor, the cases may turn into chronic CSC if SRF cannot achieve complete resolution after 2 months of treatment, we selected 2 months as the follow-up time in the principle of the human subject protection. Previous reports have used MRa to treat patients with acute CSC, but the efficacy is difficult to distinguish from spontaneous recovery. ${ }^{172124}$ To differentiate the efficacy of spironolactone from the natural course of the disease, this study included a control group in which patients were observed without any treatment.

The rate of complete resolution was higher in the MRa group than in the control group at 2 months $(56.6 \%$ vs $8.3 \%, \mathrm{p}<0.05)$, which confirmed quicker improvement in the treatment group than in the control group. Prior studies showed that the SRF achieved complete absorption an average of 8-10 weeks after the $\mathrm{LP}^{4041}$ Chan et $a l^{32}$ reported that $79.5 \%$ of patients with acute CSC had complete resolution of SRF at 1 month in a randomised controlled trial. Although the cure rate of LP and PDT is superior 
to that of our study, oral MRa has some advantages. First, it works on the entire retina rather than the specific regions. Second, it is a non-invasive intervention and has no damage to the retina. Third, it directly aims at the possible pathogenesis of CSC. Dang et $a l^{42}$ reported the cure rate of the control group $(n=26)$ in 1 and 2 months was $15.4 \%$ and $34.6 \%$, respectively. Ozkaya et al $l^{43}$ reported that $14.2 \%$ and $25.9 \%$ of the 77 patients with acute CSC achieved complete resolution at 1 and 3 months. In our study, the cure rate of the control group at 2 months was relatively low, and this may be due to the small sample size. Daruich et $a l^{3}$ reported that $25 \%$ of patients achieved complete resolution at 2 months. But the BCVA of the patients in their study was better and the duration was shorter. The lower rate of resolution in our control group could be related to the worse BCVA and longer duration.

The BCVA improved in the treatment group at each visit, but it showed significant difference only at 2 months in the observation group, probably because of the relatively slow rate of absorption. However, there was no difference between the two groups, and this may be due to the relatively good vision in patients with acute CSC. A significant decline in CMT and SRFH was observed in both groups. The mean CMT and SRFH were smaller in the treatment group at 2 months $(p<0.05)$. In our report, we also could see the significant decline of SFCT after oral MRa, while the control group did not show significant reduction, and this may remind that $\mathrm{MRa}$ was effective in the treatment of CSC and the spironolactone influenced the change of the choroidal thickness.

Previous studies have reported the side effects of spironolactone, including fatigue, dizziness, gastric pain, gynaecomastia, BP fluctuation, hyperkalaemia and so on. All the reported complications resolved after treatment interruption or switch from spironolactone to eplerenone. ${ }^{161921}$ In our study, none of the patients in the treatment group developed any side effect, and this may be because of the relatively short treatment time. In general, the drug seems well-tolerated by patients with CSC.

There were several limitations in our study, including the small sample size, and the follow-up period of only 2 months which was too short to assess the long-term safety and efficacy of MR antagonism for the treatment of acute CSC and the recurrence rate. Larger, prospective, randomised controlled clinical trials should be further investigated with longer follow-up period.

\section{CONCLUSION}

Our findings showed that oral spironolactone may achieve a faster absorption of SRF than observation in treating patients with acute CSC. About half of the eyes in the treatment group achieved complete absorption of the SRF in the short term without any side effects. MR may play an important role in some but not all patients due to the multifactorial disease. Our results may help to guide early interventions to acute CSC to achieve faster recovery for the clinicians while the patients refuse to have invasive treatment or refuse to receive no intervention. A medication guide about treatment with oral MRa should be provided to all patients with CSC in the future.

Correction notice This article has been corrected since it was published Online First. A statement about co-first authors has been added in.

Contributors SY was the guarantor of integrity of entire study. YS and WG were involved in study design. XS, YS, WF and JL were involved in data acquisition. WF and $J L$ were involved in statistical analysis. XS and YS were involved in manuscript preparation. SY and WG were involved in manuscript revision/review. SY was involved in the approval of the manuscript's final version.
Funding This research was supported by Jiangsu natural science fund projects BK20151586

Competing interests None declared.

Ethics approval The study was approved by the Ethics Committee of The First Affiliated Hospital of Nanjing Medical University.

Provenance and peer review Not commissioned; externally peer reviewed.

(C) Article author(s) (or their employer(s) unless otherwise stated in the text of the article) 2018. All rights reserved. No commercial use is permitted unless otherwise expressly granted.

\section{REFERENCES}

1 Kitzmann AS, Pulido JS, Diehl NN, et al. The incidence of central serous chorioretinopathy in Olmsted County, Minnesota, 1980-2002. Ophthalmology 2008;115:169-73.

2 Liew G, Quin G, Gillies M, et al. Central serous chorioretinopathy: a review of epidemiology and pathophysiology. Clin Exp Ophthalmol 2013;41:201-14.

3 Daruich A, Matet A, Marchionno L, et al. Acute central serous chorioretinopathy: factors influencing episode duration. Retina 2017;37:1905-15.

4 Gilbert CM, Owens SL, Smith PD, et al. Long-term follow-up of central serous chorioretinopathy. Br J Ophthalmol 1984;68:815-20.

5 Castro-Correia J, Coutinho MF, Rosas V, et al. Long-term follow-up of central serous retinopathy in 150 patients. Doc Ophthalmol 1992;81:379-86.

6 lida T, Kishi S, Hagimura N, et al. Persistent and bilateral choroidal vascular abnormalities in central serous chorioretinopathy. Retina 1999;19:508-12.

7 Giovannini A, Scassellati-Sforzolini B, D'Altobrando E, et al. Choroidal findings in the course of idiopathic serous pigment epithelium detachment detected by indocyanine green videoangiography. Retina 1997;17:286-96.

8 Kim YT, Kang SW, Bai KH. Choroidal thickness in both eyes of patients with unilaterally active central serous chorioretinopathy. Eye 2011;25:1635-40.

9 Imamura Y, Fujiwara T, Margolis R, et al. Enhanced depth imaging optical coherence tomography of the choroid in central serous chorioretinopathy. Retina 2009;29:1469-73.

10 Gass JD. Pathogenesis of disciform detachment of the neuroepithelium. Am J Ophthalmol 1967;63:1-139.

11 Bouzas EA, Karadimas P, Pournaras CJ. Central serous chorioretinopathy and glucocorticoids. Surv Ophthalmol 2002;47:431-48.

12 Zhao M, Valamanesh F, Celerier I, et al. The neuroretina is a novel mineralocorticoid target: aldosterone up-regulates ion and water channels in Müller glial cells. Faseb J 2010;24:3405-15.

13 Zhao M, Célérier I, Bousquet E, et al. Mineralocorticoid receptor is involved in rat and human ocular chorioretinopathy. J Clin Invest 2012;122:2672-9.

14 Bousquet $\mathrm{E}$, Beydoun T, Zhao M, et al. Mineralocorticoid receptor antagonism in the treatment of chronic central serous chorioretinopathy: a pilot study. Retina 2013;33:2096-102.

15 Singh RP, Sears JE, Bedi R, et al. Oral eplerenone for the management of chronic central serous chorioretinopathy. Int J Ophthalmol 2015;8:310-4.

16 Herold TR, Prause K, Wolf A, et al. Spironolactone in the treatment of central serous chorioretinopathy - a case series. Graefes Arch Clin Exp Ophthalmol 2014;252:1985-91.

17 Chin EK, Almeida DR, Roybal CN, et al. Oral mineralocorticoid antagonists for recalcitrant central serous chorioretinopathy. Clin Ophthalmol 2015;9:1449-56.

18 Ghadiali Q, Jung JJ, Yu S, et al. Central serous choriretinopathy treated with mineralocorticoid antagonists: a one-year pilot study. Retina 2016;36:611-8.

19 Daruich A, Matet A, Dirani A, et al. Oral mineralocorticoid-receptor antagonists: reallife experience in clinical subtypes of nonresolving central serous chorioretinopathy with chronic epitheliopathy. Trans/ Vis Sci Technol 2016;5:2.

20 Gergely R, Kovács I, Schneider M, et al. Mineralocorticoid receptor antagonist treatment in bilateral chornic central serous chorioretinopathy: a comparative study of exudative and nonexudative fellow eyes. Retina 2017;37:1084-1091.

21 Kapoor KG, Wagner AL. Mineralocorticoid Antagonists in the Treatment of Central Serous Chorioretinopathy: A Comparative Analysis. Ophthalmic Res 2016:56:17-22

22 Salz DA, Pitcher JD, Hsu J, et al. Oral eplerenone for treatment of chronic central serous chorioretinopathy: a case series. Ophthalmic Surg Lasers Imaging Retina 2015:46:439-44

23 Bousquet E, Beydoun T, Rothschild PR, et a/ Spironolactone for nonresolving central serous chorioretinopathy: a randomized controlled crossover study. Retina 2015;35:2505-15.

24 Maier M, Stumpfe S, Feucht N, et al. [Mineralocorticoid receptor antagonists as treatment option for acute and chronic central serous chorioretinopathy]. Ophthalmologe 2014;111:173-80.

25 Baran NV, Gürlü VP, Esgin H. Long-term macular function in eyes with central serous chorioretinopathy. Clin Exp Ophthalmol 2005;33:369-72.

26 Spaide RF, Campeas L, Haas A, et al. Central serous chorioretinopathy in younger and older adults. Ophthalmology 1996;103:2070-80. 
27 Wang M, Munch IC, Hasler PW, et al. Central serous chorioretinopathy. Acta Ophthalmol 2008;86:126-45.

28 Ficker L, Vafidis G, While A, et al. Long-term follow-up of a prospective trial of argon laser photocoagulation in the treatment of central serous retinopathy. $\mathrm{Br}$ J Ophthalmol 1988;72:829-34.

29 Loo RH, Scott IU, Flynn HW, et al. Factors associated with reduced visual acuity during long-term follow-up of patients with idiopathic central serous chorioretinopathy. Retina 2002:22:19-24.

30 Little HL. Complications of argon laser retinal photocoagulation: a five-year study. Int Ophthalmol Clin 1976;16:145-59.

31 Yap EY, Robertson DM. The long-term outcome of central serous chorioretinopathy. Arch Ophthalmol 1996;114:689-92.

32 Chan WM, Lai TY, Lai RY, et al. Half-dose verteporfin photodynamic therapy for acute central serous chorioretinopathy: one-year results of a randomized controlled trial. Ophthalmology 2008:115:1756-65.

33 Wu ZH, Lai RY, Yip YW, et al. Improvement in multifocal electroretinography after half-dose verteporfin photodynamic therapy for central serous chorioretinopathy: a randomized placebo-controlled trial. Retina 2011;31:1378-86.

34 Chan WM, Lam DS, Lai TY, et al. Choroidal vascular remodelling in central serous chorioretinopathy after indocyanine green guided photodynamic therapy with verteporfin: a novel treatment at the primary disease level. Br J Ophthalmol 2003;87:1453-8.

35 Tseng CC, Chen SN. Long-term efficacy of half-dose photodynamic therapy on chronic central serous chorioretinopathy. Br J Ophthalmol 2015;99:1070-7.
36 Lu HQ, Wang EQ, Zhang T, et al. Photodynamic therapy and anti-vascular endothelia growth factor for acute central serous chorioretinopathy: a systematic review and meta-analysis. Eye 2016;30:15-22.

37 Struthers A, Krum H, Williams GH. A comparison of the aldosterone-blocking agents eplerenone and spironolactone. Clin Cardiol 2008;31:153-8.

38 Craft J, Eplerenone CJ. Eplerenone (Inspra), a new aldosterone antagonist for the treatment of systemic hypertension and heart failure. Proc 2004;17:217-20.

39 Pichi F, Carrai P, Ciardella A, et al. Comparison of two mineralcorticosteroids receptor antagonists for the treatment of central serous chorioretinopathy. Int Ophthalmol 2016

40 Brancato R, Scialdone A, Pece A, et al. Eight-year follow-up of central serous chorioretinopathy with and without laser treatment. Graefes Arch Clin Exp Ophthalmol 1987;225:166-8.

41 Lim JW, Kang SW, Kim YT, et al. Comparative study of patients with central serous chorioretinopathy undergoing focal laser photocoagulation or photodynamic therapy. Br J Ophthalmol 2011;95:514-7.

42 Dang Y, Mu Y, Zhao M, et al. The effect of eradicating Helicobacter pylori on idiopathic central serous chorioretinopathy patients. Ther Clin Risk Manag 2013:9:355-60.

43 Ozkaya A, Alkin Z, Ozveren M, et al. The time of resolution and the rate of recurrence in acute central serous chorioretinopathy following spontaneous resolution and low-fluence photodynamic therapy: a case-control study. Eye 2016;30:1005-10 